\title{
PREDICTION OF LOW BIRTH WEIGHT BASED ON MATERNAL THIRD TRIMESTER WEIGHT AMONG MOTHERS AT A MATERNAL CLINIC IN JAKARTA, INDONESIA
}

\author{
Kusharisupeni Djokosujono $^{{ }^{*} \text {, Wahyu Kurnia Yusrin Putra }}{ }^{1}$, Diah Mulyawati Utari ${ }^{1}$, Isna Aulia Fajarini ${ }^{1}$ \\ ${ }^{1}$ Department of Public Health Nutrition, Faculty of Public Health, Universitas Indonesia, Indonesia \\ *E-mail: kusharisupeni@gmail.com
}

\begin{abstract}
The occurrence of low birth weight (LBW) can be reduced by optimizing gestational weight gain. However, the gestational weight cannot be monitored properly as there are a lot of mothers who receive Antenatal Care (ANC) less than four times as recommended by WHO. Therefore, this study aimed to determine whether early third trimester gestational weight could predict the incidence of LBW among newborns. A cross-sectional study was conducted using secondary data from Anny Rahardjo Maternity Clinic's registry. A total of 278 eligible data of pregnant mothers who visited the clinic in 2017-2018 was chosen as study subjects. The mean for weight of birth was $3112.77 \pm 384.40 \mathrm{~g}$ and early third trimester was $63.52 \pm 11.07 \mathrm{~kg}$. The prevalence of LBW was $3.2 \%$. Early third trimester weight was found as the dominant factor of LBW after controlling the length of gestation. Early third trimester weight is significantly correlated with LBW ( $<<0.001)$. The optimum cutoff point was $59.8 \mathrm{~kg}$ with $\mathrm{AUC}=0.68(\mathrm{CI} 95 \%=0.52-0.83)$, sensitivity $67 \%$, specificity $63 \%$, positive predictive value $5.66 \%$, and negative predictive value $98.2 \%$. The early third trimester weight is able to predict LBW with optimal cutoff value $59.8 \mathrm{~kg}$.
\end{abstract}

Keywords: Gestational Weight, Low Birth Weight, Pregnancy

\section{INTRODUCTION}

Low birth weight is a common public health problem in developing countries. LBW is known to be associated with higher risk of neonatal death, several chronic diseases in later life, lower academic and professional achievement, and depression (Negrato \& Gomes, 2013). The global prevalence of Low birth weight (LBW) is $15.5 \%$ where $96.5 \%$ of them are in developing countries; it is also responsible for $60-80 \%$ of neonatal deaths in the world (World Health Organization, 2018). Although the prevalence of LBW in Indonesia is considered low, it has been steadily increasing from $5.4 \%$ in $2007,5.7 \%$ in 2013 , to $6.2 \%$ in 2018 (Ministry of Health Republic of Indonesia, 2019a). The risk factors for LBW include low prepregnancy weight, poor gestational weight gain, mother's aged $<18$ or $>35$, and parity (Lima et al., 2018; Baghianimodghadam et al., 2015).

The occurrence of LBW can be predicted through the gestational weight gain, in fact the weight gain effect on birth weight was found greater than the pre-pregnancy body mass index (Lima et al., 2018). Low and suboptimal weight gain during pregnancy are correlated with infants too small for gestational age (Ota et al., 2011). Therefore, monitoring gestational weight gain during Antenatal Care (ANC) is important to prevent the occurrence of LBW. The ANC is a window of opportunity for health providers to give health-related information, so the mothers can improve their nutritional intake and gain maternal weight optimally, aligned with the recommendation of The Institute of Medicine (Institute of Medicine and National Research Council, 2009).

Unfortunately, although ANC is compulsory, the percentage of complete ANC visit is still low in developing countries, including Indonesia. Data from Indonesia Basic Health Research showed that the percentage of mothers who received ANC four times, as recommended by WHO, was merely $74.1 \%$ nationally and markedly varied within provinces, ranging from $43.8 \%$ in Papua to $90.2 \%$ in Yogyakarta (Ministry of Health Republic of Indonesia, 2019b). In developing countries, most pregnant mothers received late ANC due to low socioeconomic class, low educational background, poor social support and long distance to the hospital (Tolefac et al., 2017; Paudel et al., 2017; 
Rurangirwa et al., 2017. Thus, monitoring weekly gestational weight gain as an indicator to predict LBW is quite impossible in developing countries. However, there is an opportunity to predict LBW during the third trimester as it is the period where most mothers receive ANC and rapid gestational weight gain occurs (Bisai et al., 2009). Therefore, this study was aimed to determine whether early third trimester gestational weight could predict the pregnancy outcome in birth weight.

\section{METHODS}

The study was a secondary data analysis which conducted using cross-sectional design. The study population was the medical records of all mothers who received ANC and had labor at the Anny Rahardjo Maternity Clinic during 2017-2018 which had complete data of early third trimester weight and birth weight. The exclusion criteria were (1) Twins newborn, (2) Born pre-term $(<37$ weeks), (3) Having severe congenital disease, (4) Having other anomalies. A total of 278 mothers met these criteria and selected to be study subject. The permission to obtain data was given by the director of the Anny Rahardjo Maternity Clinic (No. 001/JP/KUAR/IV/2020).

The Anny Rahardjo Maternity Clinic, located in East Jakarta, Indonesia, was chosen as it is a well-established clinic with two general practitioners, an obstetric gynecologist, and ten trained midwives. The clinic provided ANC to approximately 300 mothers and helped 50 deliveries each month. Therefore, we considered the clinic was appropriate to be chosen as the study location.

The dependent variable of the study was birth weight, while the independent variables were length of gestation, gravida, parity, ANC visit, and early third trimester weight. Low birth weight was defined as weight $<2500 \mathrm{~g}$ which measured according to standard procedure by trained midwives (World Health Organization, 2008). Length of gestation was calculated based on the last menstrual period. The variable of gravida was defined as the total of confirmed pregnancy a mother has had, regardless the outcome of pregnancy. Meanwhile parity was defined as the total number of labour a woman has had, regardless of the outcome. The ANC visit was defined as the total of ANC received by mothers during nine months of pregnancy, while early third trimester weight was defined as the mean of the mother's weight during 24-28 weeks of gestational age (Bisai et al., 2009). The data was recorded in clinic's registry and mother's ANC handbook.

Statistical analyses: A univariate statistical analysis was performed to measure the central tendency and dispersion of the data. Correlation test were done to determine the relationship between studied variables with LBW. In order to determine the most dominant factor, logistic regression analysis using the enter method was used. All variables were included in the first modeling. Variables with $p$-value $>0.05$ were then excluded one by one. If the change in OR $>10 \%$ was observed after the variable was excluded, then the variable was returned to the model. A p-value $<0.05$ was considered as statistically significant. After the dominant factor was determined, Receiving Operating Characteristics (ROC) was used to determine the sensitivity, specificity, and cutoff value.

\section{RESULTS AND DISCUSSIONS}

The mean for birth weight was 3112.77 (SD = 384.40) g, early third trimester weight was 63.52 $\mathrm{kg} \pm 11.07 \mathrm{~kg}$, and length of gestation was 38.11 \pm 2.04 months (Table 1). The prevalence of LBW in Anny Rahardjo Maternal Clinic was 3.2\%. The majority of respondents were $\leq 30$ years old $(66.2 \%)$, multigravida (61.9\%), paucipara (57.6\%), and received $\mathrm{ANC} \geq 4$ times during pregnancy (98.2\%) (Table 2).

The assumption of independency, existence, linearity and homoscedasticity for multiple linear regressions analysis was fulfilled. The first modeling of multiple regression analysis included variable of early third trimester weight, length of gestation, parity, and ANC visit. Following that, the variable of parity and ANC visit were excluded since the p-value $>0.05$ and the changes in the OR were $<10 \%$. As a result, after controlling the length of gestation, early third trimester weight was decided to be the dominant factor of LBW (Table 3). 
Table 1. The Distribution of Studied Variables $(n=278)$

\begin{tabular}{lcc}
\hline \multicolumn{1}{c}{ Variable } & Mean \pm SD & Min - Max \\
\hline $\begin{array}{l}\text { Birth Weight }(\mathrm{g}) \\
\text { Early Third }\end{array}$ & $3112.77 \pm 384.40$ & $2100-4600$ \\
$\begin{array}{l}\text { Trimester Weight } \\
(\mathrm{kg})\end{array}$ & $63.52 \pm 11.07$ & $41.60-107.20$ \\
Maternal Age (years) & $29.06 \pm 4.40$ & $16-43$ \\
$\begin{array}{l}\text { Length of Gestation } \\
\text { (months) }\end{array}$ & $38.11 \pm 2.04$ & $37-40$ \\
Gravid & $2.12 \pm 1.12$ & $1-7$ \\
Parity & $0.96 \pm 0.91$ & $0-4$ \\
ANC Visit & $8.29 \pm 2.29$ & $3-12$ \\
\hline
\end{tabular}

Table 2. The Proportion of Studied Variables $(n=278)$

\begin{tabular}{lcc}
\hline \multicolumn{1}{c}{ Variable } & $\begin{array}{c}\text { Frequency } \\
\text { (n) }\end{array}$ & $\begin{array}{c}\text { Percentage } \\
(\%)\end{array}$ \\
\hline Birth Weight & & \\
$\quad$ Low birth weight $(<2500 \mathrm{~g})$ & 9 & 3.2 \\
$\quad$ Normal $(\geq 2500 \mathrm{~g})$ & 269 & 96.8 \\
Maternal Age & & \\
$\quad \leq 30$ Years Old & 184 & 66.2 \\
>30 Years Old & 94 & 33.8 \\
Gravid Status & & \\
$\quad$ Primigravid (1) & 96 & 34.5 \\
Multigravida (2-4) & 172 & 61.9 \\
$\quad$ Grand multigravida $(\geq 5)$ & 10 & 3.6 \\
Parity & & \\
Nullipara (0) & 102 & 36.7 \\
Paucipara (1-2) & 160 & 57.6 \\
Multipara (3-4) & 16 & 5.7 \\
ANC Visit & & \\
< 4 times & 5 & 1.8 \\
$\geq 4$ times & 273 & 98.2 \\
\hline
\end{tabular}

Table 3. Final Modelling of Dominant Factor of Low Birth Weight

\begin{tabular}{lcc}
\hline \multicolumn{1}{c}{ Variable } & p-value & OR \\
\hline Early Third Trimester Weight & 0.000 & 10.99 \\
Length of Gestation & 0.002 & 32.45 \\
\hline
\end{tabular}

The result of ROC analyses is presented in Figure 1. The area under the curve (AUC) of early third trimester weight was 0.68 (CI 95\% $=0.52-$ 0.8 ). The optimum cutoff point to predict LBW was $59.8 \mathrm{~kg}$ with sensitivity $67 \%$ and specificity $63 \%$, mothers with early third trimester weight $\leq 59.8$ had higher risk to have $\mathrm{LBW}$ newborns $(\mathrm{OR}=3.38$ (CI $95 \%=0.82-13.8$ ) The positive predictive value was $5.66 \%$ and negative predictive value

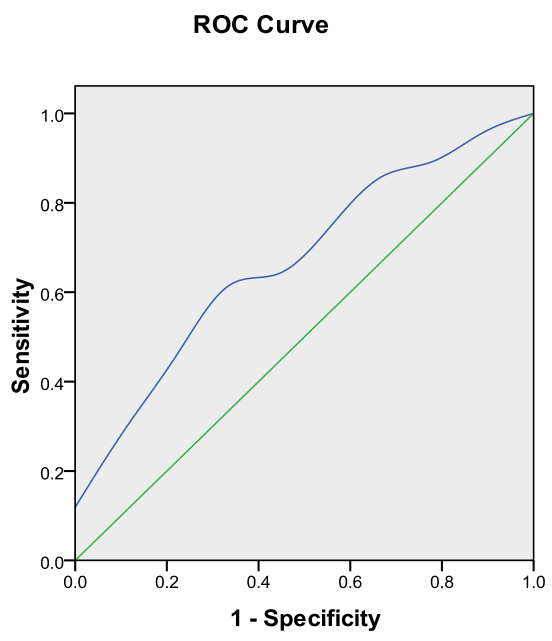

Figure 1. ROC for Early Third Trimester Weight and Low Birth Weight

was $98.2 \%$. With the cutoff $59.8 \mathrm{~kg}$, we found that the prevalence of LBW was $2.42 \%$.

Low birth weight is still a significant public health problem in developing countries. The result of the current study found that the prevalence of LBW was $3.2 \%$. This is lower than the prevalence of Indonesia in national level (6.2\%) and neighboring countries, including Malaysia $(11.3 \%)$ and Brunei Darussalam (10.8\%) (Ministry of Health Republic of Indonesia, 2019b; WHO, 2019). The low prevalence was probably because the majority of respondents made at least four ANC visits during pregnancy $(98.2 \%)$., the complete adherence to ANC visit is able to reduce the risk of LBW as the mothers receive nutritional counselling during the visit (Haftu et al., 2018; Zhou et al., 2019). Moreover, most of respondents were paucipara $(57.6 \%)$ and multigravida $(61.9 \%)$; the researches have concluded that the birth weights of paucipara and multigravida infants were heavier compared to nullipara and primigravida (Hinkle et al., 2014; Momeni et al., 2017).

The early third trimester is the best period to prevent LBW since huge number of mothers received first ANC during the second or third trimester, thus their weight can be measured in this period (Gupta \& Talukdar, 2017). As much as 50\% of plasma volume increase, which proportional with the birthweight of the baby, happens during third trimester (Soma-Pillay et al., 2016). Mother's weight during this period is positively correlated with birth weight (Yang et al., 2017). Therfore, if 
during early third trimester the mother's weight is less than recommendation, it is still corrigible to optimize the fetal growth. In the present study, we found that the early third trimester weight was the dominant factor of LBW after controlling the length of gestation. We also found that the weight was able to predict LBW with sensitivity $67 \%$ and specificity $63 \%$. This result is similar to another study which found that early third trimester weight is optimal to identify LBW with sensitivity $52.3 \%$ dan specificity 71.4\% (Bisai et al., 2009). Thus, we concluded that early third trimester was the best period to detect LBW. Health interventions to prevent LBW should be done during this period.

The Institute of Medicine has a guideline for minimum weight gain to prevent LBW (Institute of Medicine and National Research Council, 2009). However, the guideline is inapplicable in rural settings as most mothers don't measure their prepregnancy weight and gestational weight weekly from the first trimester. Therefore, the present study attempted to find the optimum cutoff value of early third trimester weight to predict LBW. We found that mothers with early third trimester weight $\leq 59.8 \mathrm{~kg}$ had a higher risk to have LBW infants. This cutoff is higher compared the results of studies by Sachin et al. (2011) and Bisai (2009) which were $55 \mathrm{~kg}$ and $48 \mathrm{~kg}$ respectively (Bisai et al., 2009; Mumbare et al, 2012; Sudha et al., 2017). This was probably due to the difference in respondent characteristics of gestational weight gain. The mean of the mother's weight in the current study was $63.52 \pm 384.40 \mathrm{~kg}$, while Bisai et al. (2009) was $49.45 \pm 324 \mathrm{~kg}$ (Bisai et al., 2009).

\section{CONCLUSION}

The early third trimester weight is able to predict LBW with optimal cutoff value 59.8 $\mathrm{kg}$. The present study has a limitation; we did not consider the pre-pregnancy BMI effect on pregnancy weight as the data of pre-pregnancy BMI was unavailable. This study was conducted in a clinical setting in an urban area, yet the prevalence of low birth weight is higher in a remote area. Therefore, the above findings should be validated in the community settings with larger samples. The low prevalence of LBW might also affect result of our findings.

\section{ACKNOWLEDGEMENT}

The authors would like to thank the director and midwives of the Anny Rahardjo Maternity Clinic for permitting us to use the data for research purpose.

\section{REFERENCES}

Baghianimoghadam, M., Baghianimodghadam, B., Ardian, N., \& Alizadeh, E. (2015). Risk factors of low birth weight and effect of them on growth pattern of children up to sixth months of life: A cross-sectional study. J Educ Health Promot, 4(40), 1-4. doi:10.4103/2277-9531.157226

Bisai, S., Dtta, N., Bose, K., Mahalanabis, D., \& Sen, A. (2009). Receiver Operating Characteristics (ROC) Curve Estimation of Low Birth Weight Based on Maternal Early Third Trimester Weight among Bengalee Wome of Kolkata, India. Coll Antropol, 3, 725-728.

Gupta, R., \& Talukdar, B. (2017). Frequency and Timing of Antenatal Care Visits and Its Impact on Neonatal Mortality in EAG States of India. Journal of Neonatal Biology, 6(3). doi:10.4172/2167-0897.1000263

Haftu, A., Hagos, H., Mehari, M., \& G/her, B. (2018). Pregnant women adherence level to antenatal care visit and its effect on perinatal outcome among mothers in Tigray Public Health institutions, 2017: cohort study. BMC Res Notes, 11, 1-6. doi:10.1186/s13104-018-3987-0

Hinkle, S., PS, A., Mendola, P., Sjaarda, L., E, Y., Boghossian, N., \& Laughon, S. (2014). The association between parity and birthweight in a longitudinal consecutive pregnancy cohort. Paediatr Perinat Epidemiol, 28(2), 1-15. doi:10.1111/ppe.12099

Institute of Medicine and National Research Council. (2009). Weight Gain During Pregnancy: Reexamining the Guidelines. Washington (DC): National Academies Press. Retrieved from https://www.ncbi.nlm.nih.gov/books/ NBK32813/ doi: 10.17226/12584

Lima, R., Batista, R., Ribeiro, M., Ribeiro, C., Simoes, V., Neto, P., . . B Bettiol, H. (2018). Prepregnancy body mass index, gestational weight gain, and birth weight in the BRISA cohort. Rev Saude Publica, 52(46), 1-10. doi:10.11606/S1518-8787.2018052000125

Ministry of Health Republic of Indonesia (2019a). Key Results of Basic Health Research 2018. Jakarta: Ministry of Health Republic of Indonesia. 
Ministry of Health Republic of Indonesia. (2019b). Basic Health Research 2018. Jakarta: Ministry of Health Republic of Indonesia Repulic of Indonesia.

Momeni, M., Danaei, M., Kermani,A., Bakhshandeh, M., Foroodnia, S., \& Mahmoudabadi, Z. (2017). Prevalence and Risk Factors of Low Birth Weight in the Southeast of Iran. International Journal of Preventive Medicine, 8(12), 8-15. doi:10.4103/ijpvm.IJPVM_112_16

Mumbare, S., Maindarkar, G., Darade, R., Yenge, S., \& Tolani. (2012). Maternal risk factors associated with term low birth weight neonates: A matched-pair case control study. Indian Pediatrics, 49(1), 25-28. doi:10.1007/s13312012-0010-z

Negrato, C., \& Gomes, M. (2013). Low Birth Weight: Causes and Consequences. Diabetol Metab Syndr, 5 (49), 1-8. doi:10.1186/17585996-6-60.

Ota, E., Haruna, M., Suzuki, M., Anh, D., Tho, L., Tam, N., \& Thiem, D. e. (2011). Maternal body mass index and gestational weight gain and their association with perinatal outcomes in Viet Nam. Bull World Health Organ, 89 (2), 127-137. doi:10.2471/BLT.10.077982

Paudel, Y., Jha, T., \& Mehata, S. (2017). Timing of First Antenatal Care (ANC) and Inequalities in Early Initiation of ANC in Nepal. Frontier in Public Health, 5(242), 1-6. doi:10.3389/ fpubh.2017.00242

Rurangirwa, A., Morgen, I., Nyirazinyonye, L., Ntaganira, J., \& Krantz, G. (2017). Determinants of poor utilization of antenatal care services among recently delivered women in Rwanda; a population based study. BMC Pregnancy and Childbirth, 17, 1-10. doi:https://doi.org/10.1186/ s12884-017-1328-2
Soma-Pillay, P., Catherine, N., Tolppanen, H., Mebazaa, A., Tolppanen, H., Mebazaa, A. (2016). Physiological Changes in Pregnancy. Cardiovascular Journal of Africa, 27(2), 89-94. doi: 10.5830/CVJA-2016-021

Sudha, G., Reddy, T., Narasimhulu, S., \& Reddy, K. R. (2017). Prevalence and Correlates of Low Birth Weight in Chittoor District of Andhra Pradesh, India. Gynaecology International Journal, 7(1), 1-5. doi:10.15406/ogij.2017.07.00233

Tolefac, P., Halle-Ekane, G., Agbor, V., Sama, C., Ngwasiri, C., \& Tebeu, P. (2017). Why do pregnant women present late for their first antenatal care consultation in Cameroon? Maternal Health, Neonatology, and Perinatology, 2(29), 1-6. doi:10.1186/s40748-017-0067-8

World Health Organization. (2008). Training Course on Child Growth Assessment. Geneva: WHO.

World Health Organization. (2018). Care of the Preterm and Low Birth Weight Newborn Low Prematurity Day - 17 November 2018. Retrieved July 28, 2019, from http://origin. who.int/maternal_child_adolescent/newborns/ prematurity/en/

World Health Organization. (2019). UNICEf/ WHO Low Birth Weight Estimates. Geneva: World Health Organization. Retrieved from https:// data.unicef.org/wp-content/uploads/2014/10/ Low-birthweight-data-2000-2015.xlsx

Yang, W., Han, F., Gao, X., Chen, Y., Ji, L., \& Cai, X. (2017). Relationship Between Gestational Weight Gain and Pregnancy Complications or Delivery Outcome. Nature Research Journal, 7 , 1-9. doi:10.1038/s41598-017-12921-3

Zhou, H., Wang, A., Huang, X., Guo, S., Yang, Y., Martin, K., \& X, T. (2019). Quality antenatal care protects against low birth weight in 42 poor counties of Western China. PLoS One, 14(1), 1-14. doi:10.1371/journal.pone.0210393 